Article

\title{
Fluid Flow in Cotton Textile: Effects of Wollastonite Nanosuspension and Aspergillus Niger Fungus
}

\author{
Ayoub Esmailpour ${ }^{1}$, Hamid R. Taghiyari ${ }^{2}{ }^{*}$, Reza Majidi Najafabadi ${ }^{3}$, Amin Kalantari ${ }^{2}$ and \\ Antonios N. Papadopoulos $4, *$ (D) \\ 1 Department of Physics, Faculty of Sciences, Shahid Rajaee Teacher Training University, Tehran 16788-15811, \\ Iran; esmailpour@sru.ac.ir \\ 2 Wood Science and Technology Department, Faculty of Materials Engineering \& New Technologies, \\ Shahid Rajaee Teacher Training University, Tehran 16788-15811, Iran; amin1359k@yahoo.com \\ 3 Department of Restoration, Central Tehran Branch (IAU-CTB), Islamic Azad University, Poonak Sq., \\ Ashrafi Esfehani Ave., Tehran 15847-43311, Iran; r.majidi.n@gmail.com \\ 4 Department of Forestry and Natural Environment, International Hellenic University, \\ GR-661 00 Drama, Greece \\ * Correspondence: htaghiyari@sru.ac.ir (H.R.T.); antpap@for.ihu.gr (A.N.P.)
}

Received: 2 November 2019; Accepted: 27 November 2019; Published: 2 December 2019

\begin{abstract}
Aspergillus niger is a common contaminant in food industry, laboratories, and also a potential threat to biological works of art in museums. Cotton textiles have frequently been used in museums for canvas paintings. In the present project, the effect of Aspergillus niger on fluid flow rate of nanowollastonite-impregnated cotton textile specimens was investigated. Cotton specimens were impregnated with nanowollastonite (NW) suspension at four concentrations of $10 \%, 20 \%, 30 \%$, and $40 \%$ to be further compared with control specimens. Results showed that fluid flow in cotton textile was as high as $361.3 \mathrm{~cm}^{3} \cdot \mathrm{s}^{-1}$ due to its high porous structure and very low compactness of fibers (low density). Impregnation with NW did not have a significant effect on fluid flow in cotton textile. Exposure to Aspergillus niger increased fluid flow in control specimens as a result of deterioration of cotton fibers. Exposure of NW-impregnated specimens at concentrations more than $20 \%$ to Aspergillus niger did not have any significant effect on fluid flow. In control specimens, fungus mycelium penetrated deep into the texture of textile. However, in NW-impregnated specimens, the fungus could not penetrate into the texture and deteriorate the specimens. It was concluded that NW can be recommended for textile industry and also works of art as they protect cotton textiles against Aspergillus niger while, do not diminishi its dying and paintability properties.
\end{abstract}

Keywords: biological resistance; cotton textile; permeability; wollastonite; Aspergillus niger

\section{Introduction}

Fungi spores can move easily even by air movement, landing on precious materials such as papers and textiles in museums. Exposure of historical objects in museums to fungi is inevitable. Textiles made from ligno-cellulose and biomaterials can therefore be degraded by different deteriorating agents such as fungi [1-5]. Cotton textiles are basically cellulose fibers woven together; this makes them vulnerable to a variety of fungi species, including Aspergillus, Penicillium, Chaetomium, Trichoderms, and Alternaria species [3]. The genus Aspergillus has many species, including Aspergillus niger. As a common fungus species, it is a troublesome fungus that causes a disease called black mold, is contaminant of different edible materials (such as fruits and vegetables), and it grows on cellulosic materials too. The easy access of this fungus to artistic objects in museums makes them at constant risk of being destroyed. Many fungicide and polymers and nanomaterials have so far been experimented to increase biological 
resistance of textiles and fabrics in museums [3]. Abdel-Kareem [4] used four polymers mixed with different fungicides. Some dominant fungi isolated from ancient Egyptian textiles were used to be tested on sample textiles. The cited author reported increased durability and reinforcement of the textiles. Though, improvement was observed in the abovementioned research projects, application of chemicals and polymers as fungicides are to be limited in favor of more environmentally friendly materials. Wollastonite is mineral material, having no environmental contamination and being safe regarding human health; moreover, its application on historical objects would have no harm on the objects themselves [6-8]. It has shown high efficacy to limit fungi growth on lingo-cellulosic materials such as cotton textiles and papers by simple spraying or dipping in a wollastonite suspension, and wood and wood-composites by impregnation and mixing with resins [9-11]. Therefore, in the present project, wollastonite was used to find out if it can have hindering effects on the growth of fungi on cotton textiles which are constantly used in paintings of museums. In order to increase effectiveness of wollastonite and to benefit from the advantages of materials at nanoscale [12-16], wollastonite nanosuspension with four concentrations were used to impregnate cotton textile specimens. Specimens were then exposed to Aspergillus niger [17], as a dominant fungus species in Moghadam Museum of University of Tehran. This fungus was extracted and identified from historic embroidery at the abovementioned museum (Figure 1). This embroidery contains colored silk textile pieces that are sewn on a cotton substrate (Figure 2). Colored silk threads were used to create shapes on silk textiles, and also to sew silk textile pieces and cotton substrate together (Figure 3).
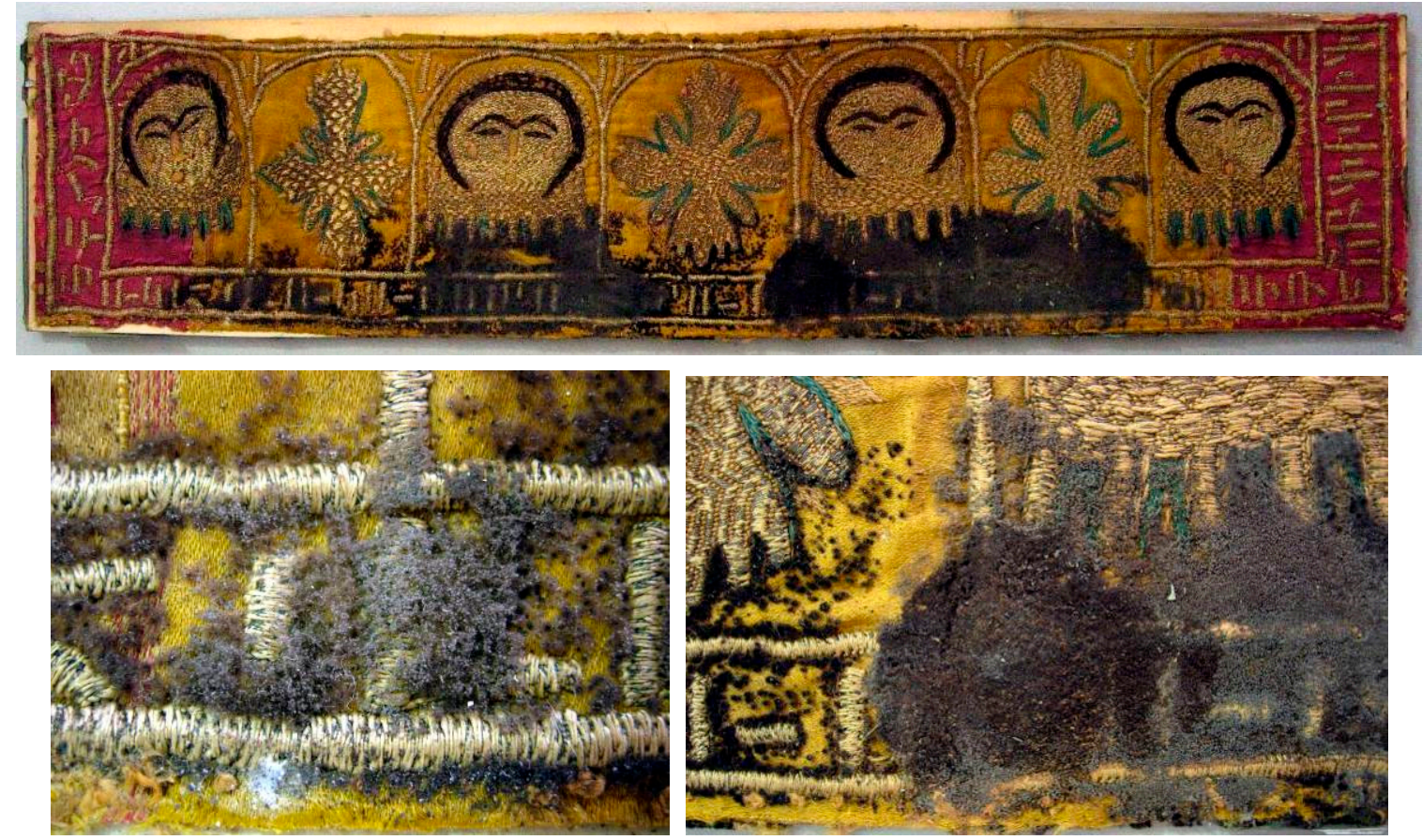

Figure 1. Front view of the historic embroidery at Moghadam museum (Tehran) contaminated with Aspergillus niger fungus. 

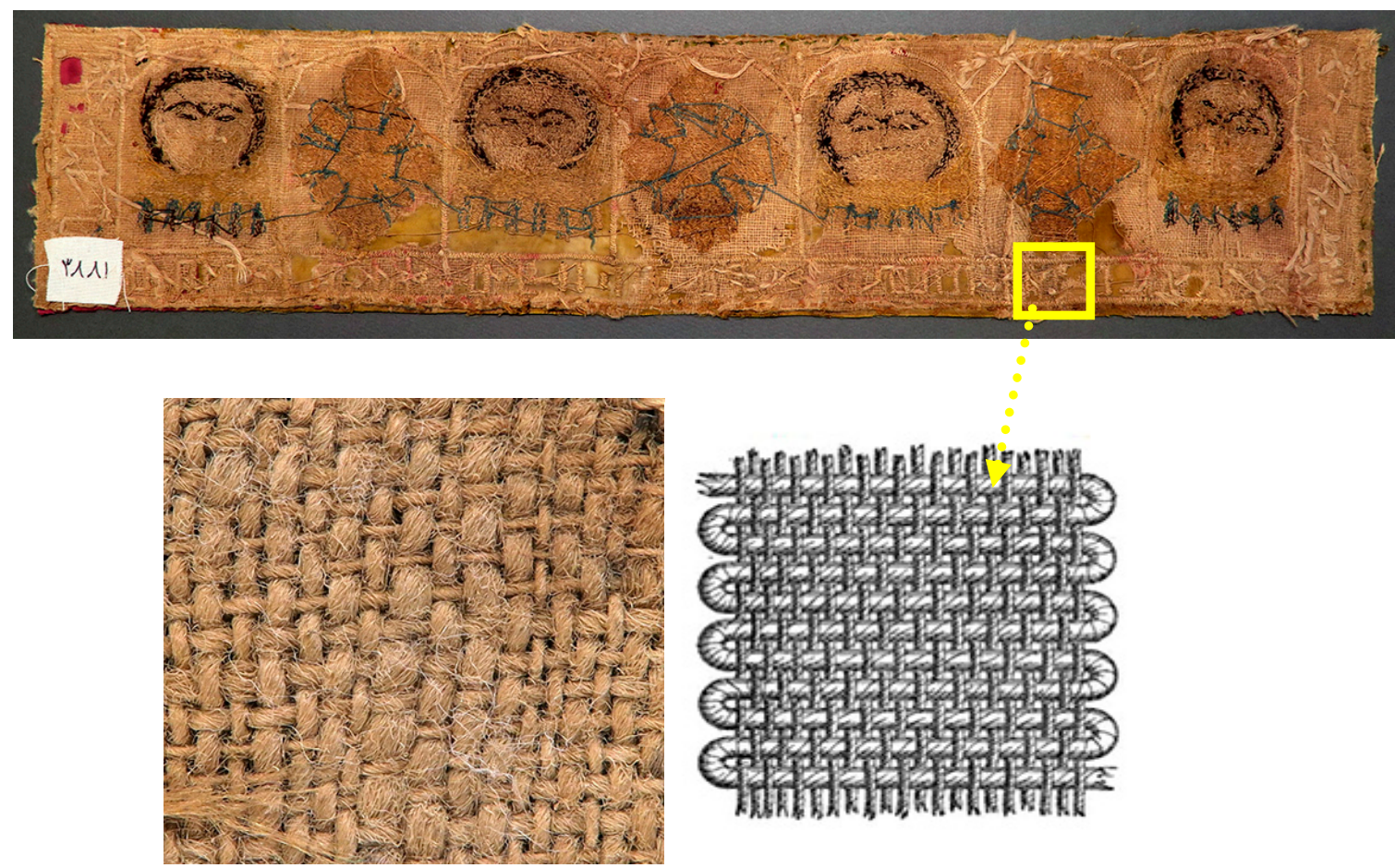

Figure 2. Back view of the historic embroidery at Moghadam museum (Tehran) showing the cotton substrate on which silk textile pieces were sewn.
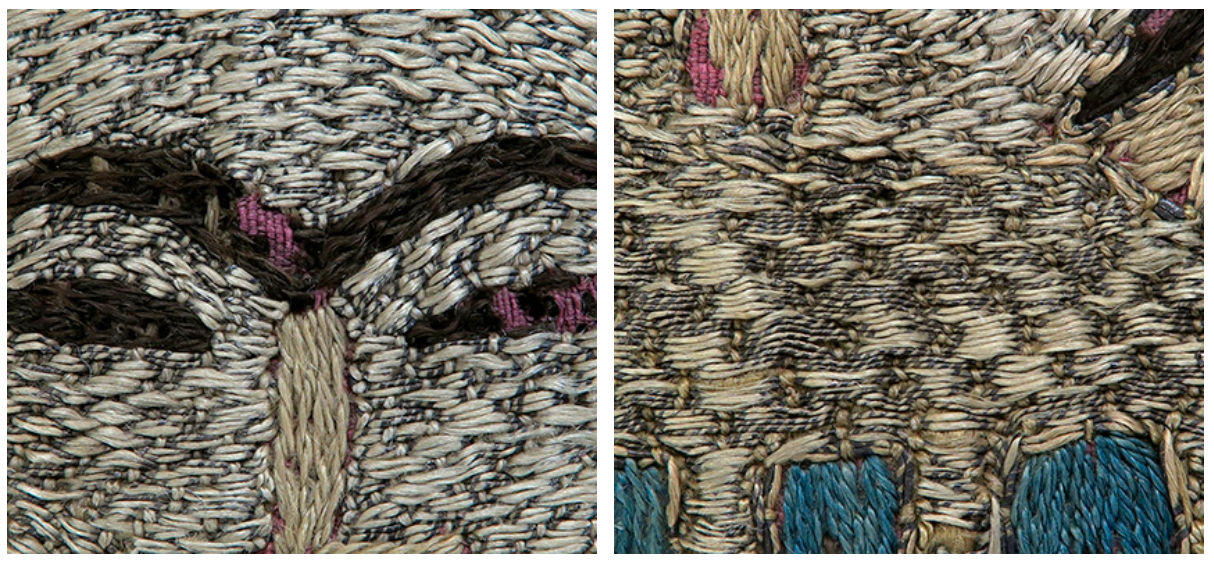

Figure 3. Shapes created by silk threads stitches on the historic embroidery at Moghadam museum (Tehran).

Though previous studies have already illustrated the effectiveness of nano-wollastonite (NW) in preserving ligno-cellulose materials, including some textiles that are used in museums $[9,10,17,18]$, further studies should be done to investigate other properties of currently used textiles as to the importance of artistic objects in museums. Therefore, the present project was carried out to elaborate on permeability, as an important physical property that ultimately affects dying and printability in textiles.

\section{Materials and Methods}

\subsection{Specimen Preparation and Nano-Wollastonite Impregnation}

White cotton textile with no dye was purchased from Tehran Central Bazaar. Specimens were prepared with dimensions of $40 \times 40 \mathrm{~mm}$ (Figure 4). Specimens were randomly divided into six groups. Four sets of specimens were impregnated with nano-wollastonite suspension (NW) with $10 \%, 20 \%$, 
$30 \%$, and $40 \%$ concentrations. For preparation of NW-suspension with the target concentration for example $20 \%, 20 \mathrm{~g}$ of nano-wollastonite gel (based on the dried weight) was mixed with an appropriate amount of distilled water (in this case, $80 \mathrm{~g}$ distilled water). The mixture was then mixed for $20 \mathrm{~min}$ by a magnetic stirrer. Once NW-suspensions with the target concentration were prepared, cotton specimens were dipped in them for $30 \mathrm{~s}$, during which they were gently shaken steadily. After being impregnated, each specimen was separately hung up to dry $\left(25 \pm 2{ }^{\circ} \mathrm{C}\right.$; relative humidity $\left.40 \%-43 \%\right)$. The results of permeability measurement of different NW-treated specimens were finally compared with those of the control specimens (without NW impregnation). For each group, 20 specimens were prepared; in total, 100 specimens were tested in the present study.

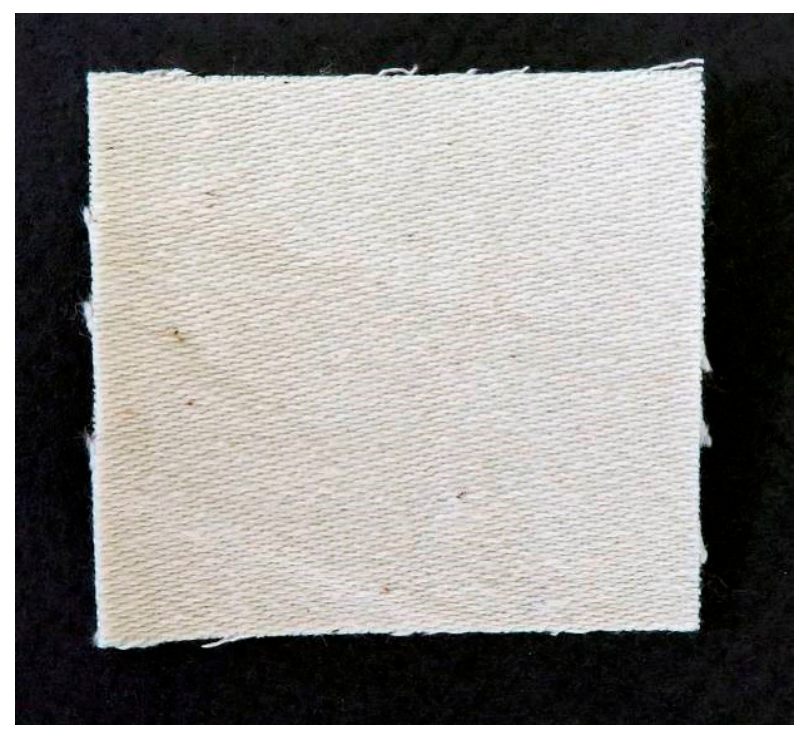

Figure 4. Photograph of fluid flow samples with dimensions of $40 \times 40 \mathrm{~mm}$.

At least 70\% of wollastonite nanofibers ranged from 30 to $110 \mathrm{~nm}$. Specifications of wollastonite compounds and formulations were as presented in Table S1 (Supplementary Material No. 1). Once impregnated, specimens were hung to season for 6 weeks before being exposed to Aspergillus niger fungus. The control specimens were exposed to the fungus under the same conditions. Before and after the impregnation, fluid flow in all specimens was measured for comparison purposes.

\subsection{Volumetric Flow Rate Measurement}

Flow rate was measured by an apparatus to measure air permeability in continuous porous media [19]. The volume displacement of falling-water was measured to determine volumetric flow rate [20]. Milli-second precision was used to measure the volume of the falling-water. The $40 \times 40 \mathrm{~mm}$ specimens were put in a special holder for measurement of the air flow rate; diameter of the flow area of paper specimens were set according to air resistance of paper, Gurley method (Figure 5). The whole system was airtight. Pressure difference $(\Delta P)$ was monitored in milli-bar precision [20]. An electronic time measurement device was connected to the apparatus to determine the time with milli-second precision. As the volume in the water tube could easily be measured, the volumetric flow rate was calculated in terms of $\mathrm{cm}^{3} \mathrm{~s}^{-1}$. 


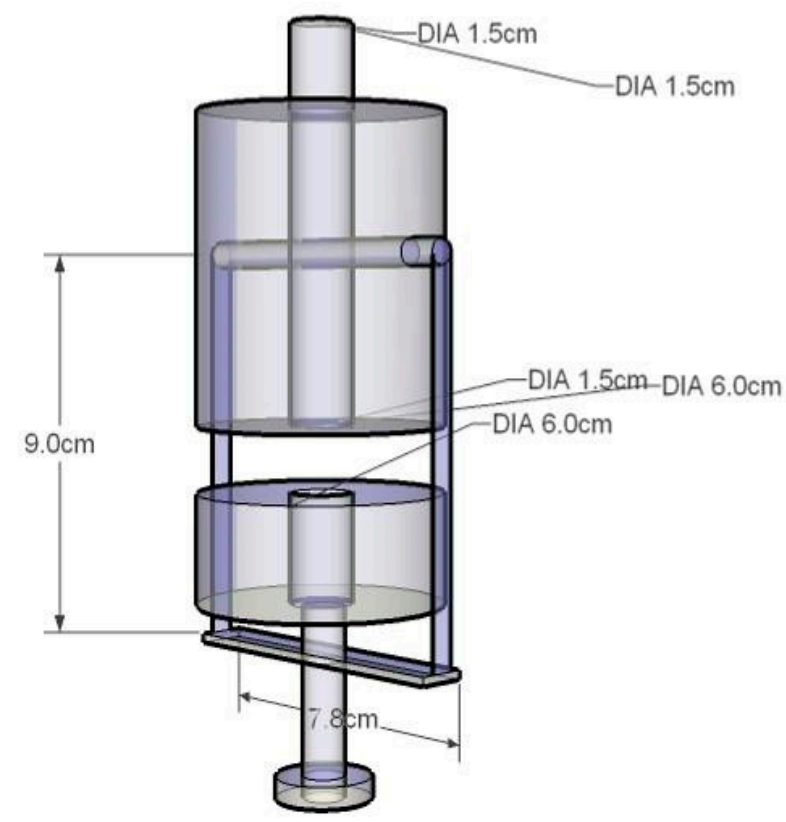

Figure 5. Paper holder for flow rate measurement in paper specimens.

\subsection{Fungal Exposure}

In the present study, cotton textile specimens were first dried at $103 \pm 2{ }^{\circ} \mathrm{C}$ for $24 \mathrm{~h}$ in a hot air oven. The weight of each specimens was measured before and after fungal exposure. Once dried, they were exposed to $A$. niger for 3 months in Petri dishes. Petri dishes were inoculated 3 weeks before cotton specimens were placed in them to be exposed to $A$. niger. In order to make sure all specimens were exposed to the same density of $A$. niger, only those Petri dishes were selected in which $A$. niger mycelia covered $70 \%-80 \%$ of the substrate nourishing substance.

The incubation process was performed at the National Library and Archives of I. R. of Iran on Sabouraud's agar $\left(25 \pm 1{ }^{\circ} \mathrm{C}\right.$ and $45 \% \pm 2 \%$ relative humidity). Mycelia that were grown on the specimens were then carefully removed and specimens were dried again before the final fluid flow measurement.

\section{Results and Discussion}

Results of the flow rate measurement demonstrated that the permeability in cotton textile was high compared to other cellulosic materials such as paper, wood, and wood-composites; flow rate in the control specimens of cotton textile was $361.3 \mathrm{~cm}^{3} \cdot \mathrm{s}^{-1}$ (Figure 6). A previous study reported that fluid flow rate in historical paper was as low as $29 \mathrm{~cm}^{3} \cdot \mathrm{s}^{-1}$. Density of the cotton textile in the present project was $0.51 \mathrm{~g} \cdot \mathrm{cm}^{-3}$, while the density of the historical paper was $1.15 \mathrm{~g} \cdot \mathrm{cm}^{-3}$. This indicated that compactness ratio in the historical paper was significantly higher in comparison to the cotton textile. Therefore, fluid could more easily pass through the voids and spaces in between the fibers in cotton textile. In fact, the higher density in the historical paper can be translated into a more integrated matrix, and lower voids and spaces in between the fibers, ultimately hindering any fluids to pass through. Cross-sectional macrophotos of control specimens showed large cavities in between fibers, allowing fluid to easily pass through (Figure 7). 


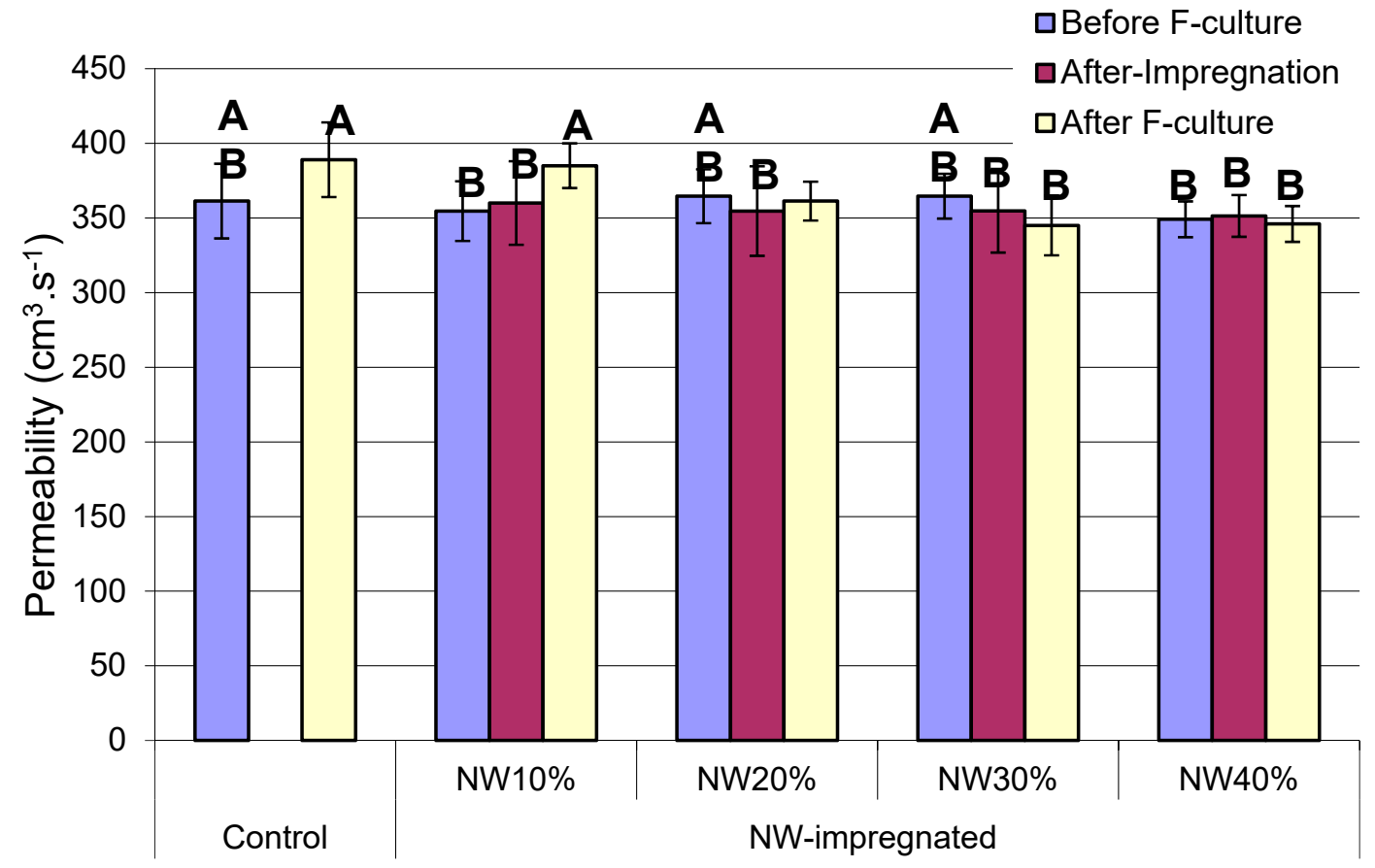

Figure 6. Volumetric flow rate $\left(\mathrm{cm}^{3} \cdot \mathrm{s}^{-1}\right)$ in the textile specimens before and after being impregnated with wollastonite nanosuspension and after being exposed to $A$. niger fungus ( $\mathrm{NW}=$ nanowollastonite; $\mathrm{F}=$ fungus-exposed) (letters on each column represent Duncan groupings at $95 \%$ level of confidence).

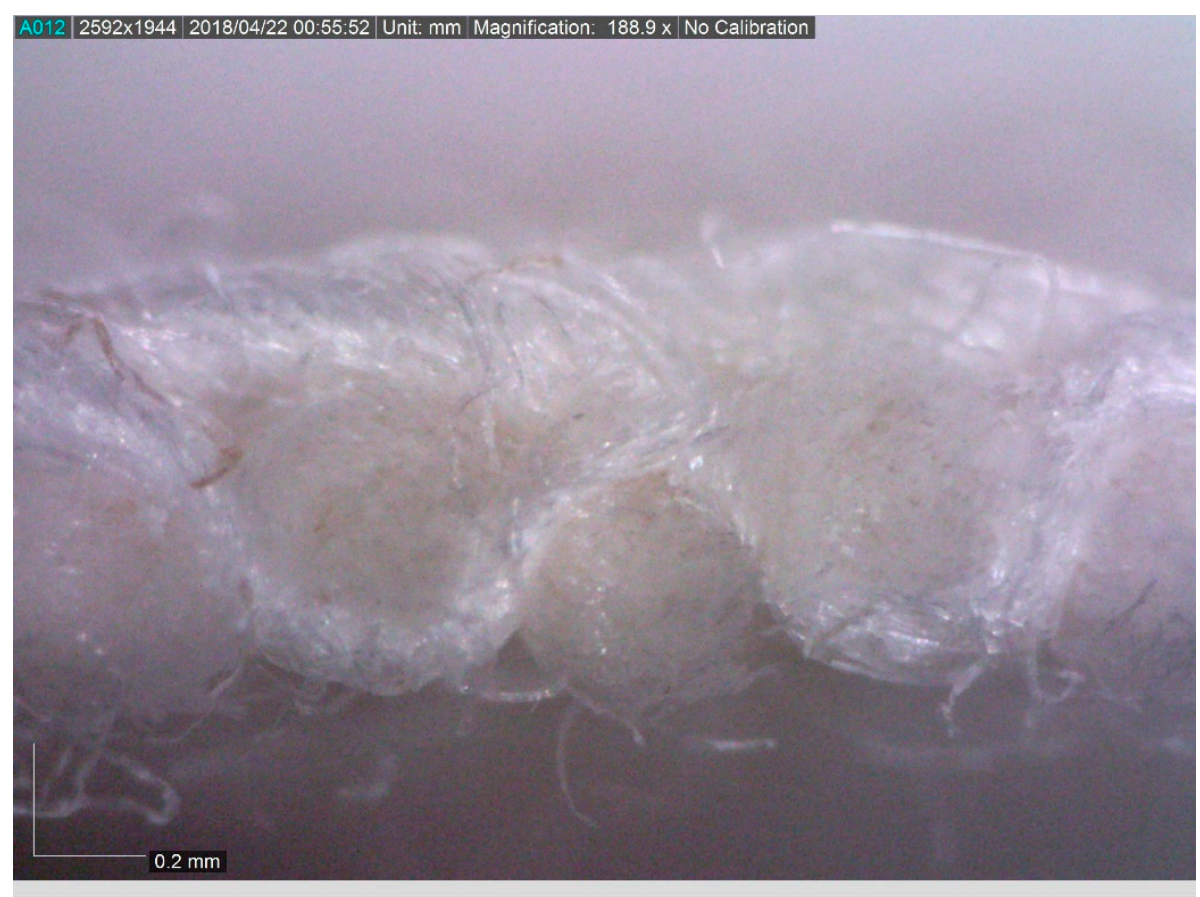

Figure 7. Cross-sectional of control textile specimen showing large cavities in between fibers for transfer of fluid.

NW-impregnation did not have any significant effect on flow rate (Figure 6). Considering the significant effect of NW-impregnation on historical paper, and bearing in mind its higher density and compaction ratio, this may indicate that the porous structure in cotton textile specimens was so wide that the formation of new bonds between Calcium atoms in wollastonite and oxygen atoms in the hydroxyl 
groups of the cellulose chains could not alter its fluid flow behavior [21,22]. In this connection, density functional theory (DFT) previously illustrated that the optimal adsorption distance and adsorption energy for NW on cellulose were $1.7 \AA$ and $-6.6 \mathrm{eV}$, respectively [22], that are considerably high.

Once exposed to Aspergillus niger, only the control and NW-10\% specimens showed an increase in fluid flow rate $(7.5 \%$ and $8.5 \%$ in the control and NW-10\%, respectively). The increase was attributed to the deteriorating effect of Aspergillus niger on textile fibers, decreasing their integrity and eventually, allowing a larger volume of air to pass through. The same deteriorating effect was reported to have caused considerable decline in tensile stress of cotton textile [18]. The similar increase in fluid flow rate in the control and NW-10\% specimens indicated that $10 \%$ of NW is not enough to significantly hinder the growth of $A$. niger on cotton textile. On the other hand, higher NW concentrations (NW-20\%, NW-30\%, and NW-40\%) demonstrated a decrease in flow rates (Figure 6). A previous research project demonstrated that NW concentration of $20 \%$ significantly improved the biological resistance of cotton textile in a way that tensile stress values in the fungal-exposed NW-impregnated specimens were significantly similar to those of the control specimens [18]. Based on the above discussion, it was concluded that higher NW concentrations preserved the overall structure of cotton textile in a way that fungi mycelium could not penetrate deeply into textile structure and deteriorate it; instead the mycelium had to spread on the outer layer of textile specimens. Microscopic images of the surface of cotton specimens showed $A$. niger mycelium to fully grow and fill in the voids and empty spaces among the cotton fibers, regardless of being impregnated with NW or not (Figure 8a-c). However, the cross-sectional view of specimens demonstrated that in control and NW- $10 \%$ specimens, Aspergillus niger mycelium penetrated into deep parts of the textile profile cut (Figure 9a). However, in specimens impregnated with higher NW concentrations, mycelium had a tendency to accumulate only on the surface layers (Figure 9b).

The r-square value of $66 \%$ between fluid flow values versus tensile stress indicated that although fluid flow in cotton textile as a porous media was closely in relation with the integrity of the overall matrix, other elements were also involved in the process (Figure 10). In this connection, considering highly significant decreasing effect of fungal exposure on tensile stress and tensile strain values in a previous study [18], higher increase in fluid flow was expected. However, it is to be noted that growth of thick mycelium network on and within voids and spaces of control specimens partially blocked the way through transfer of fluid (Figure 9a). In fact, an increase in weight was reported in specimens as a result of being exposed to Aspergillus niger [18]. Therefore, fluid flow rate could not increase higher. In the NW-40\% specimens though, Aspergillus niger could not easily grow into the texture and the growth was rather superficial (Figure 9b). Contour and surface plots clearly showed a steady decreasing trend in fluid flow as tensile strain and tensile stress values decreased (Figure 11).

Cluster analysis based on the properties of fluid flow, and tensile stress and strain values clearly revealed that exposure to Aspergillus niger fungus had a nearly similar effect on the control and NW- $10 \%$ specimens (Figure 12). This similarity was also observed in the fluid flow values of these two treatments (Figure 6). Therefore, it is concluded that NW suspension with $10 \%$ of concentration would not be sufficient to significantly improve biological resistance of cotton textile against Aspergillus niger fungus. Other treatments demonstrated close cluster-grouping, indicating an overall similarity among them. Therefore, nearly any of the $20 \%, 30 \%$, or $40 \%$ NW-concentrations can be recommended. 


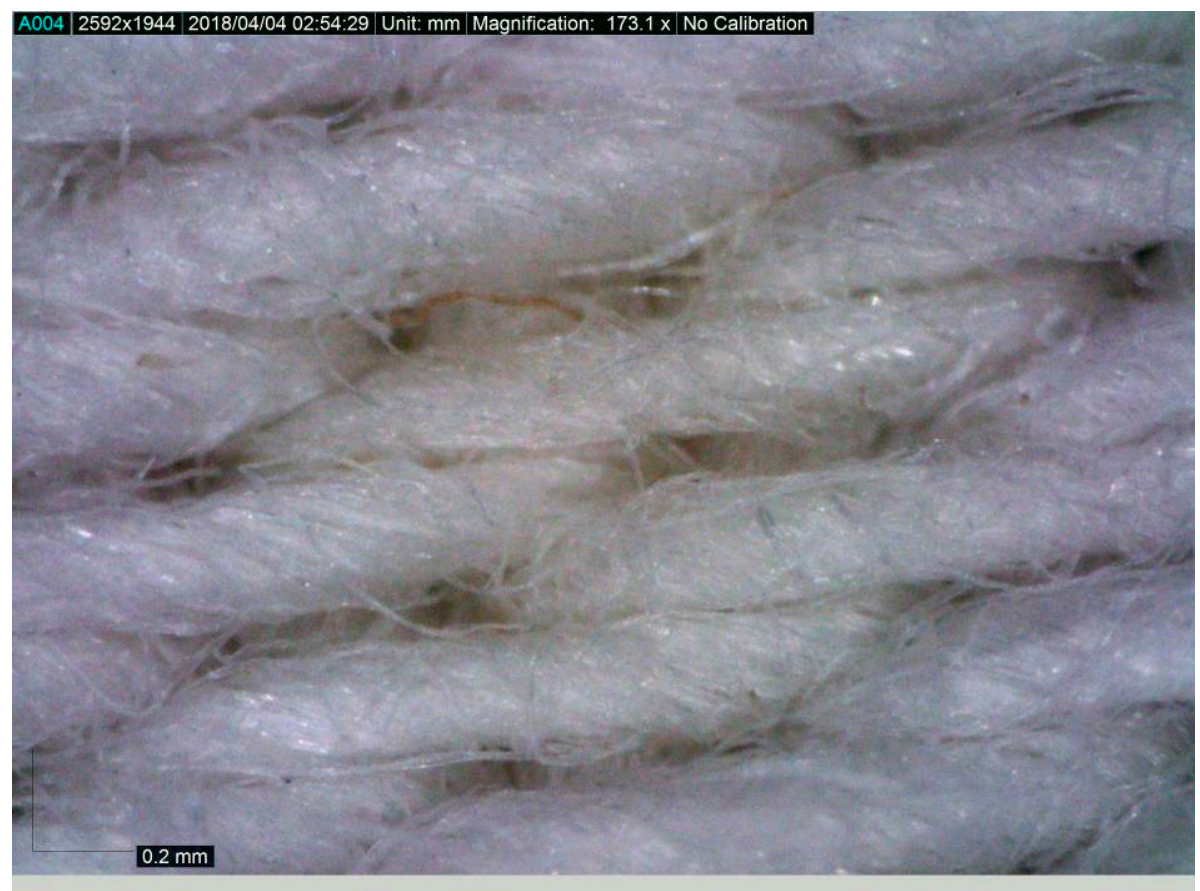

(a)

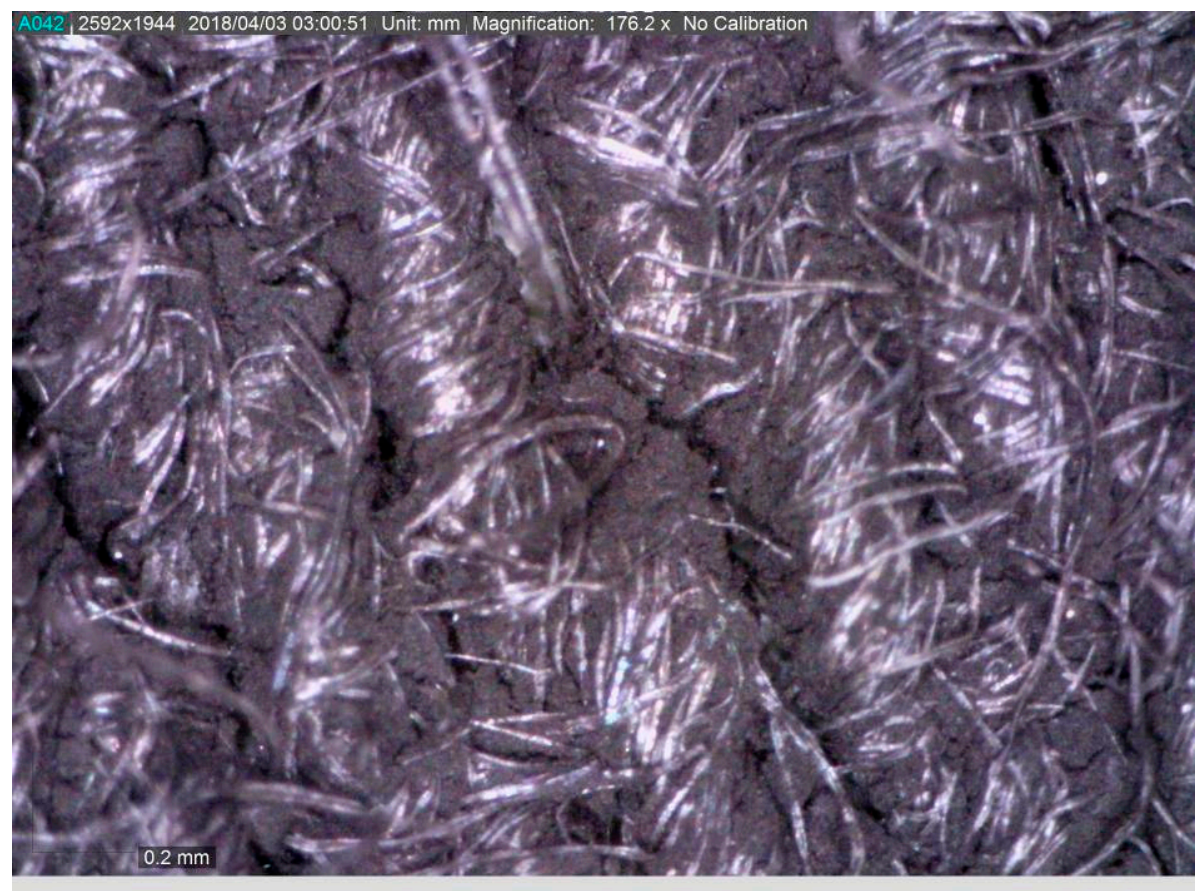

(b)

Figure 8. Cont. 


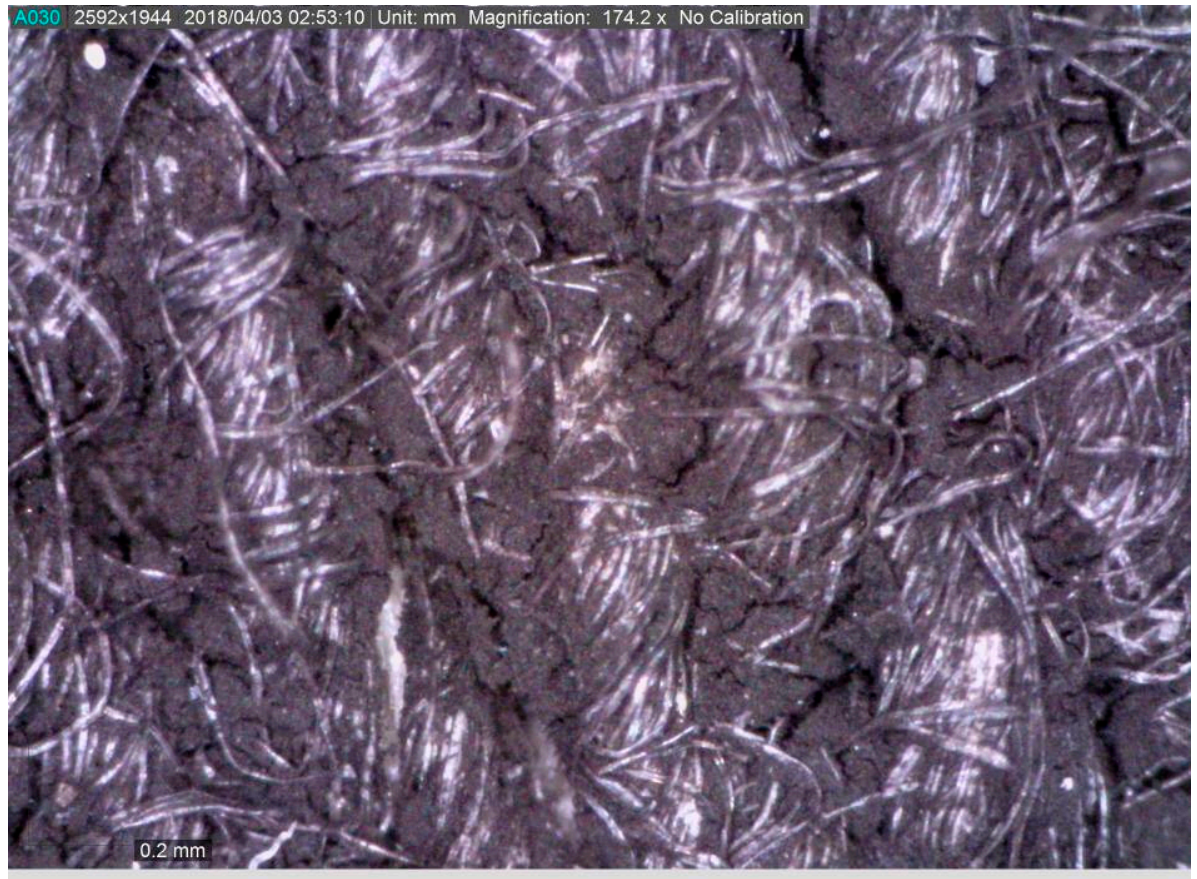

(c)

Figure 8. Surface views of a control with no fungal exposure (a), as well as control (b) and NW-40\% (c) specimens after being exposed to $A$. niger.

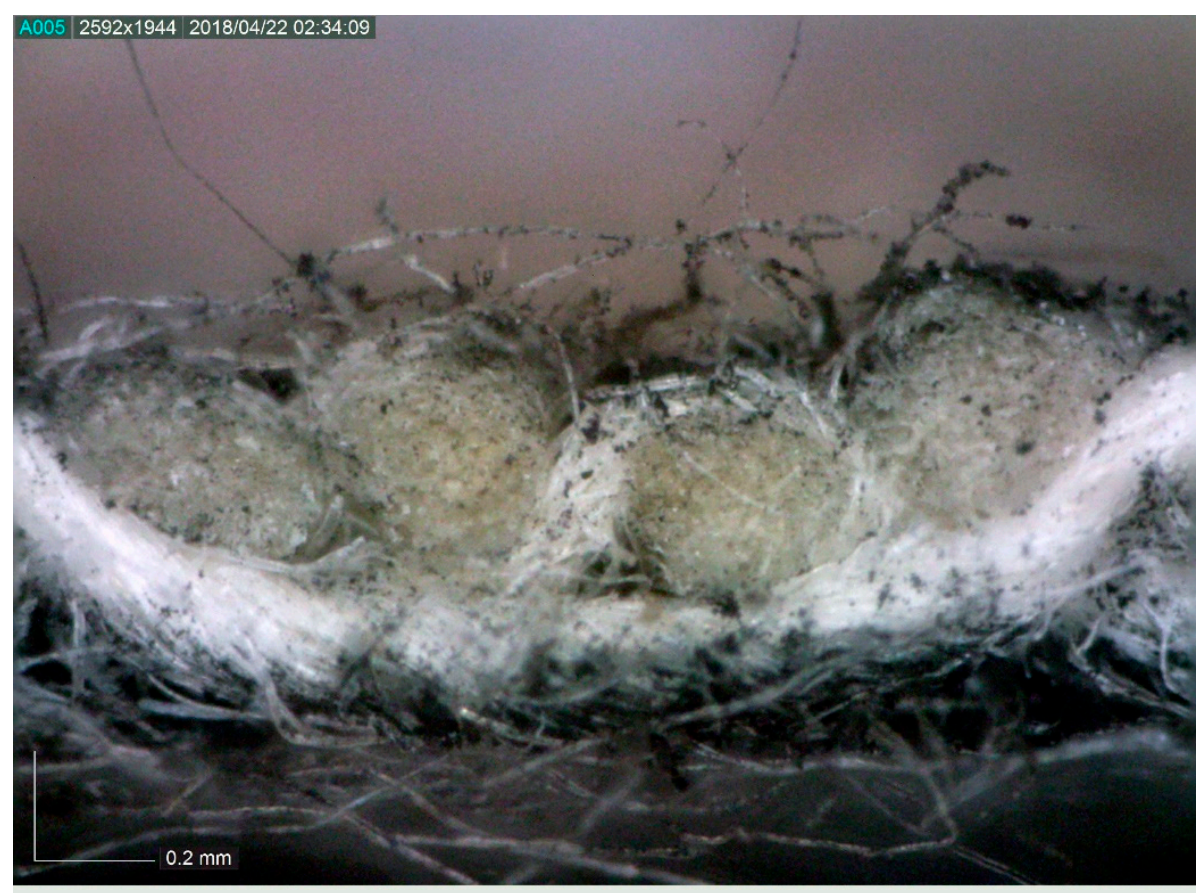

(a)

Figure 9. Cont. 


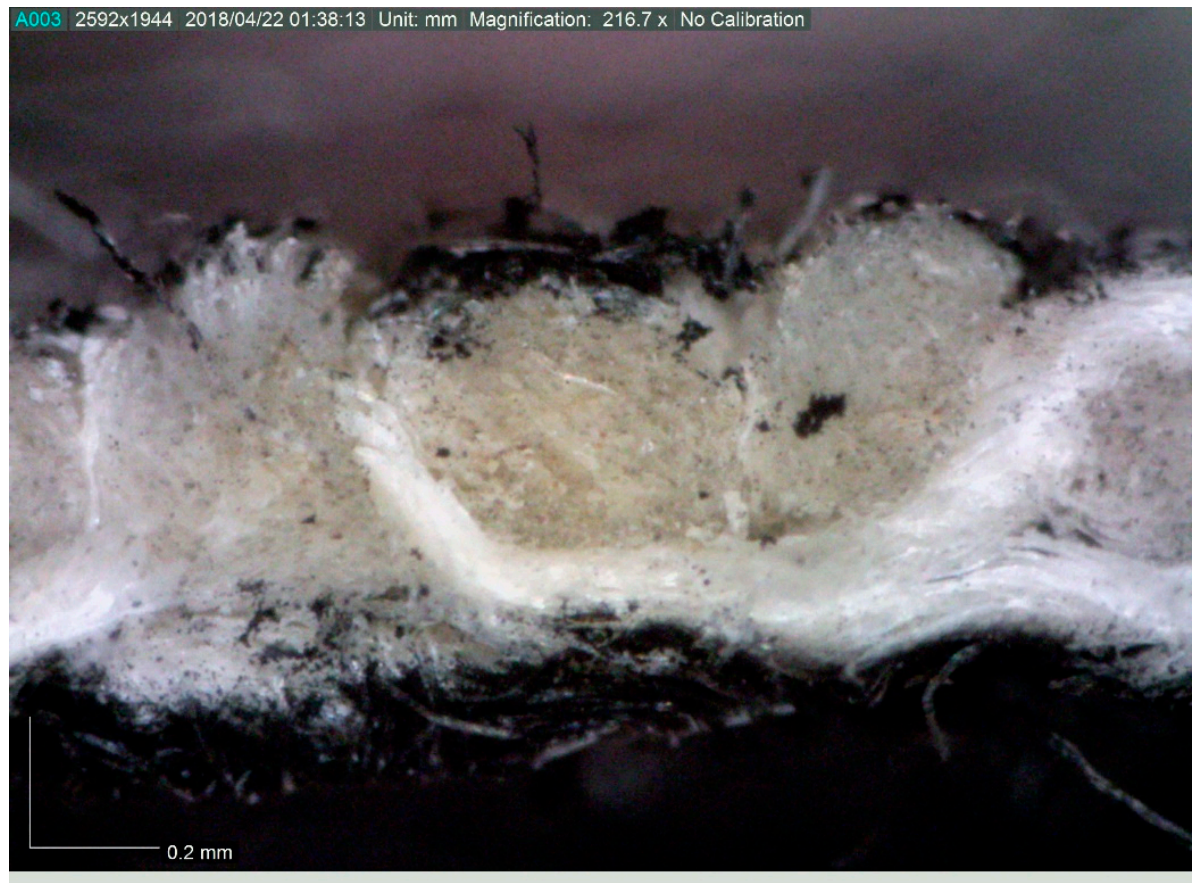

(b)

Figure 9. Cross-sectional of fungus-cultured specimens showing penetration of $A$. niger mycelium in deeper parts of control specimens (a), and accumulation of mycelium in the surface layers of NW- $40 \%$ (b).

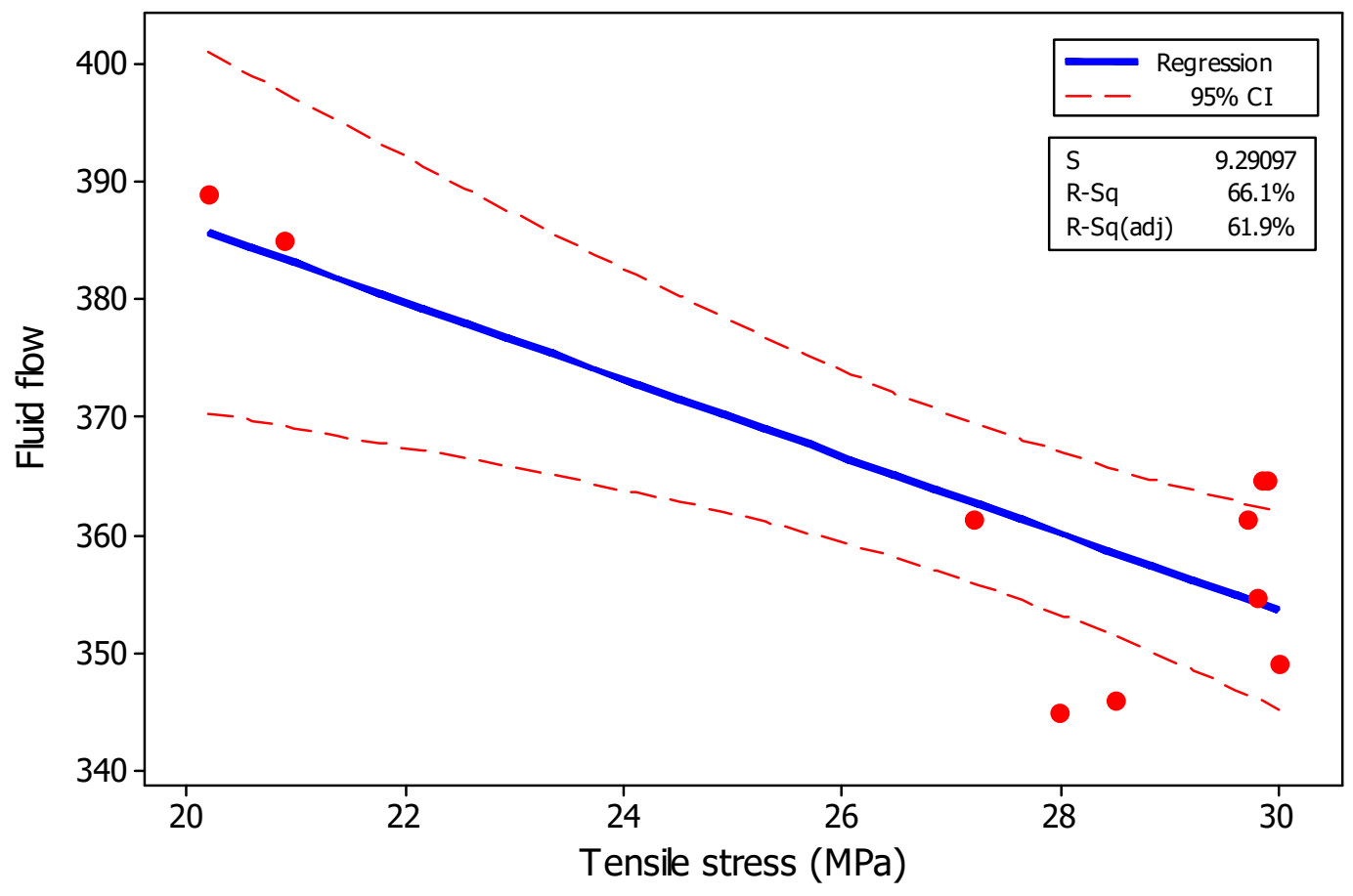

Figure 10. Fitted-line plot between fluid flow versus tensile stress values. 

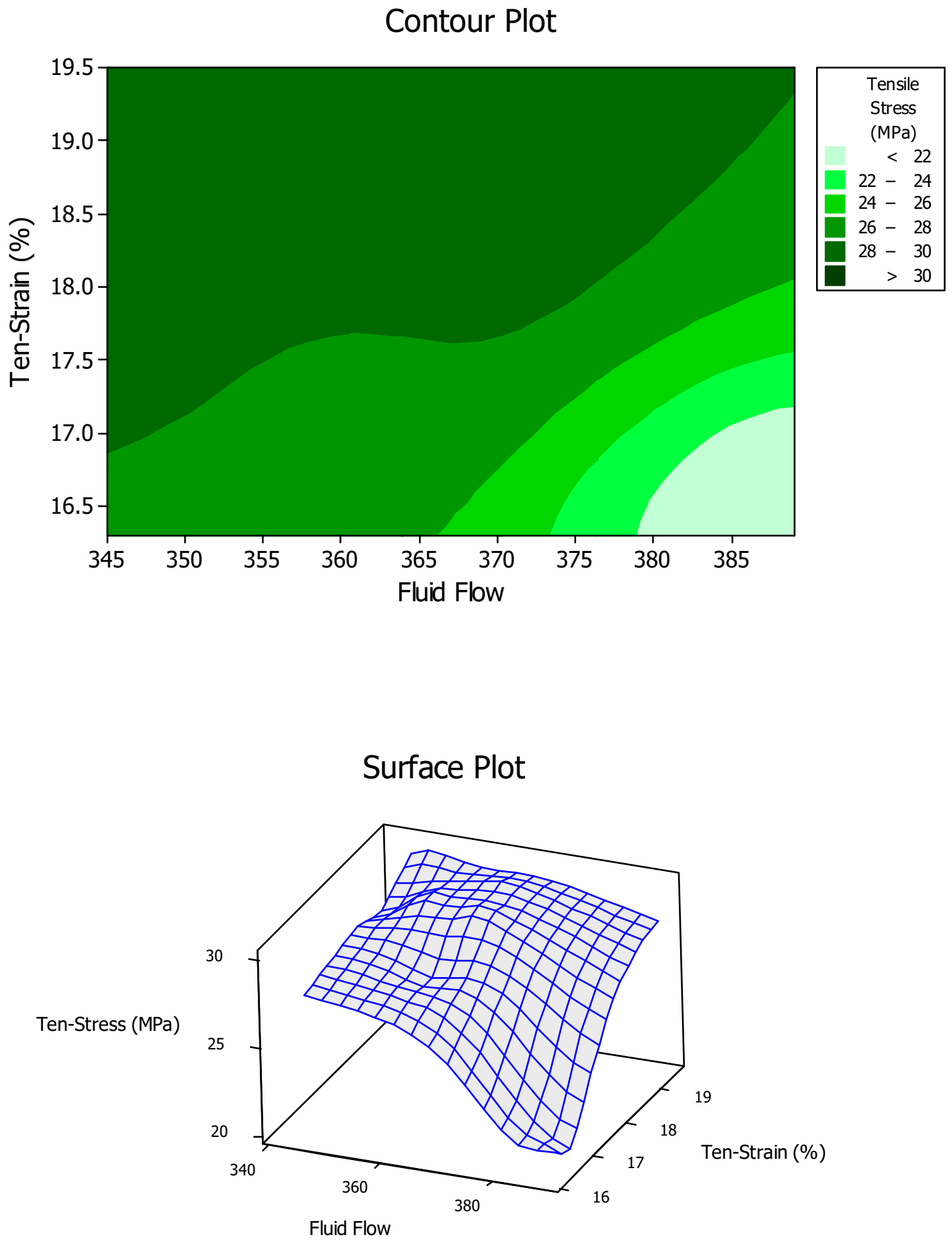

Figure 11. Contour and surface plots among tensile stress and tensile strain versus fluid flow values (Ten-Stress = tensile stress; Ten-Strain = tensile strain). 


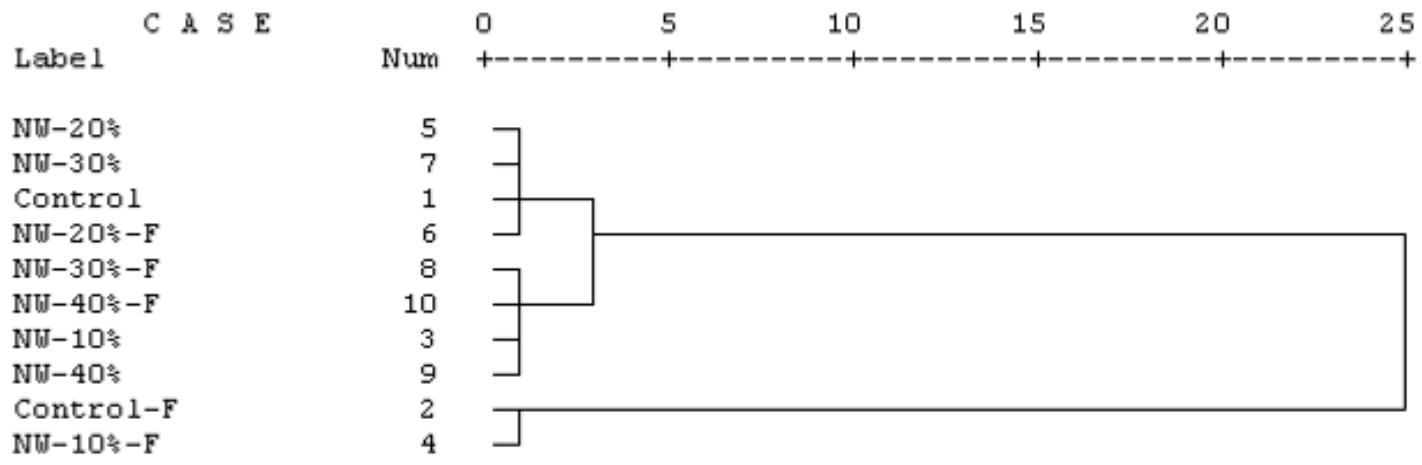

Figure 12. Cluster analysis of the control and NW-impregnated cotton textile specimens based on tensile stress and strain, as well as fluid flow, values before and after exposure to A. niger fungus for 3 months ( $\mathrm{F}=$ fungal-exposed; $\mathrm{NW}=$ nano-wollastonite).

\section{Conclusions}

The aim of this study was to investigate the effects of Aspergillus niger on fluid flow of cotton textiles impregnated with four concentrations of nanowollastonite. Exposure to Aspergillus niger increased fluid flow rate in control specimens as a result of deterioration of fibers in cotton specimens and it was found that fungus mycelium can penetrate deep into the texture of textile. In nanowollastonite impregnated specimens, the growth of Aspergillus niger occurred mainly on the superficial layers of cotton textile and fluid flow rate with concentrations higher than $20 \%$, remained rather intact with a slight tendency to decrease in value. It is concluded that impregnation with nanowollastonite suspensions can be recommended for textile industry and for canvas paintings because it does not change fluid flow as a vital criterion in textile determining dying and paintability of textiles and fabrics, while protecting these materials against deterioration by Aspergillus niger. However, as impregnation can affect surface roughness and, therefore, dying and paintability of textiles and fabrics would change, further studies on surface roughness and paintability should be undertaken to conclude on this point.

Supplementary Materials: The following are available online at http://www.mdpi.com/2227-9717/7/12/901/s1, Table S1: Compounds of the nano-wollastonite gel used for treatment purpose at four concentration levels of 10, 20,30 , and $40 \%$.

Author Contributions: Methodology, H.R.T., A.E. and R.M.N.; Validation, H.R.T. and R.M.N.; Investigation, R.M.N. and A.K.; Writing-Original Draft Preparation, H.R.T., A.E. and A.N.P.; Writing-Review \& Editing, H.R.T., and A.N.P.; Visualization, H.R.T. and R.M.N; Supervision, H.R.T.

Funding: This research received no external funding.

Acknowledgments: We appreciate Olaf Schmidt (Dept. of Wood Biology, University of Hamburg) for his valuable scientific consultation and support, as well as Alexander von Humbolt Stiftung, Germany.

Conflicts of Interest: The authors declare no conflict of interest.

\section{References}

1. Schmidt, O. Wood and Tree Fungi: Biology, Damage, Protection and Use; Springer: Berlin/Heidelberg, Germany, 2006.

2. Schmidt, O. Indoor wood-decay basidiomycetes: Damage, causal fungi, physiology, identification and characterization, prevention and control. Mycol. Prog. 2007, 6, 261-279. [CrossRef]

3. Abdel-Kareem, O. Monitoring, controlling and prevention of the fungal deterioration of textile artifacts in the museum of Jordanian Heritage. Mediterr. Archaeol. Archaeom. 2010, 10, 85-96.

4. Abdel-Kareem, O. Fungal deterioration of historical textiles and approaches for their control in Egypt. Morana RTD 2010, 7, 40-47.

5. Karim, M.; Ghodskhah-Daryaei, M.; Torkaman, J.; Oladi, R.; Tajick Ghanbary, M.A.; Bari, E.; Yilgor, N. Natural decomposition of hornbeam wood decayed by the white rot fungus Trametes versicolor. Anais Acad. Bras. Ciênc. 2017, 89, 2647-2655. [CrossRef] [PubMed] 
6. Huuskonen, M.S.; Jarvisalo, J.; Koskinen, H.; Nickels, J.; Rasanen, J.; Asp, S. Preliminary results from a cohort of workers exposed to wollastonite in a Finnish limestone quarry. Scand. J. Work Environ. Health 1983, 9, 169-175. [CrossRef] [PubMed]

7. Huuskonen, M.S.; Tossavainen, A.; Koskinen, H.; Zitting, A.; Korhonen, O.; Nickels, J.; Korhonen, K.; Vaaranen, V. Wollastonite exposure and lung fibrosis. Environ. Res. 1983, 30, 291-304. [CrossRef]

8. Maxim, L.D.; McConnell, E.E. A review of the toxicology and epidemiology of wollastonite. Inhal. Toxicol. 2005, 17, 451-466. [CrossRef]

9. Taghiyari, H.R.; Bari, E.; Schmidt, O.; Ghanbary, M.A.T.; Karimi, A.; Tahir, P.M.D. Effects of nanowollastonite on biological resistance of particleboard made from wood chips and chicken feather against Antrodia vaillantii. Int. Biodeterior. Biodegrad. 2014, 90, 93-98. [CrossRef]

10. Taghiyari, H.R.; Bari, E.; Schmidt, O. Effects of nanowollastonite on biological resistance of medium-density fiberboard against Antrodia vaillantii. Eur. J. Wood Wood Prod. 2014, 72, 399-406. [CrossRef]

11. Hassani, V.; Taghiyari, H.R.; Schmidt, O.; Maleki, S.; Papadopoulos, A.N. Mechanical and physical properties of Oriented Strand Lumber (OSL): The effect of fortification level of nanowollastonite on UF resin. Polymers 2019, 11, 1884. [CrossRef]

12. Majidi, R. A biosensor for hydrogen peroxide detection based on electronic properties of carbon nanotubes. Mol. Phys. 2012, 111, 89-93. [CrossRef]

13. Majidi, R. Electronic properties of graphyne nanotubes filled with small fullerenes: A density functional theory study. J. Comput. Electron. 2016, 15, 1263-1268. [CrossRef]

14. Mantanis, G.; Terzi, E.; Kartal, S.N.; Papadopoulos, A. Evaluation of mold, decay and termite resistance of pine wood treated with zinc- and copper- based nanocompounds. Int. Biodeterior. Biodegrad. 2014, 90, 140-144. [CrossRef]

15. Lykidis, C.; Bak, M.; Mantanis, G.; Neméth, R. Biological resistance of pine wood treated with nano-sized zinc oxide and zinc borate against brown-rot fungi. Eur. J. Wood Wood Prod. 2016, 74, 909-911. [CrossRef]

16. Pethig, R. Review-Where is dielectrophoresis (DEP) going? J. Electrochem. Soc. 2017, 164, 3049-3055. [CrossRef]

17. Sobral, L.V.; Melo, K.N.; Souza, C.M.; Silva, S.F.; Silva, G.L.R.; Silva, A.L.F.; Wanderley, K.A.A.; Oliveira, I.S.; Cruz, R. Antimicrobia and enzymatic activity of anemophilous fungi of a public university in Brazil. Anais Acad. Bras. Ciênc. 2017, 89, 2327-2356. [CrossRef]

18. Taghiyari, H.R.; Majidinajafabadi, R.; Vahidzadeh, R. Wollastonite to hinder growth of Aspergillus niger fungus on cotton textile. Anais Acad. Bras. Cienc. 2018, 90, 2797-2804. [CrossRef] [PubMed]

19. Taghiyari, H.R.; Moradi Malek, B. Effect of heat treatment on longitudinal gas and liquid permeability of circular and square-shaped native hardwood specimens. Heat Mass Transf. 2014, 50, 1125-1136. [CrossRef]

20. Taghiyari, H.R.; Kalantari, A.; Ghorbani, M.; Bavaneghi, F.; Akhtari, M. Effects of fungal exposure on air and liquid permeability of nanosilver- and nanozincoxide-impregnated Paulownia wood. Int. Biodeterior. Biodegrad. 2015, 105, 51-57. [CrossRef]

21. Taghiyari, H.R. Effects of nanosilver-impregnation and alfalfa-intercropping on fluid transfer in downy black poplar wood. Maderas Cienc. Tecnol. 2014, 16, 49-62. [CrossRef]

22. Taghiyari, H.R.; Majidi, R.; Jahangiri, A. Adsorption of nanowollastonite on cellulose surface: Effects on physical and mechanical properties of medium-density fiberboard (MDF). Cerne 2016, 22, 215-222. [CrossRef]

(C) 2019 by the authors. Licensee MDPI, Basel, Switzerland. This article is an open access article distributed under the terms and conditions of the Creative Commons Attribution (CC BY) license (http://creativecommons.org/licenses/by/4.0/). 